Jurnal Spektrum Komunikasi Vol. 7 N0. 1, Juni 2019

\title{
PENGARUH TERPAAN TAYANGAN YOUTUBE "LONDOKAMPUNG" TERHADAP TINGKAT PENGETAHUAN BAHASA SUROBOYOAN PADA SUBSCRIBERS DI SURABAYA
}

\section{THE EFFECT OF "LONDOKAMPUNG" YOUTUBE SHOW ON THE SUROBOYOAN LANGUAGE KNOWLEDGE LEVEL IN SUBSCRIBERS IN SURABAYA}

\author{
${ }^{1}$ Ismojo Herdono, ${ }^{2}$ Arinda Wahyu Ningtyas \\ Program Studi Ilmu Komunikasi Stikosa-AWS, Surabaya \\ Email : ismojo.herdono@gmail.com
}

\begin{abstract}
This study aims to determine how the influence of Youtube shows "londokampung" on the level of knowledge of the Suroboyoan language on subscribers in Surabaya. The "londokampung" program discusses the culture in Surabaya and its delivery uses the Suroboyoan language. What makes the show interesting is the creator content from "londokampung" is an Australian citizen named Dave Jepchott, he is so fluent in pronunciation and writing in the Suroboyoan language. This type of research is a quantitative study by distributing questionnaires to Youtube subscribers "londokampung" with a sample of 100 respondents. The analytical method used in this study is "Simple Liner Regression" to determine the strength of the relationship between a show on YouTube with the audience. The data obtained is then processed using SPSS version 16.0. The results of this study have a significant relationship between the effect of watching YouTube shows "londokampung" with the level of knowledge of Suroboyoan language on subscribers in Surabaya. based on the results of correlation analysis and simple linear regression that the influence variable YouTube shows "londokampung" has a significant relationship with the value of the correlation coefficient of 0.581 to the variable knowledge of the Suroboyoan language on mediumvalue subscribers. The correlation value in this study is in the coefficient interval between 0,400-0,599.
\end{abstract}

Keywords: Youtube londokampung, Knowledge of Surboyoan Language, Increased Knowledge

\footnotetext{
ABSTRAK

Penelitian ini bertujuan untuk mengetahui bagaimana pengaruh tayangan Youtube "londokampung" terhadap tingkat pengetahuan bahasa Suroboyoan pada subscribers di Surabaya. Tayangan "londokampung" membahas kebudayaan yang ada di Surabaya dan penyampaiannya menggunakan bahasa Suroboyoan. Yang membuat menarik dari tayangan tersebut yakni konten kreator dari "londokampung" merupakan warga negara Australia bernama Dave Jepchott, ia begitu fasih dalam pengucapan maupun penulisan dengan bahasa Suroboyoan. Jenis penelitian ini merupakan penelitian kuantitatif dengan menyebarkan kuesioner kepada subscribers Youtube "londokampung" dengan sampel sebanyak 100

ISSN 2338 - 0861 (cetak); e-ISSN 2621 - 8712 (online)

website : http://spektrum.stikosa-aws.ac.id
} 
responden. Metode analisis yang digunakan dalam penelitian ini adalah "Regresi Liner Sederhana" untuk mengetahui kuat rendahnya hubungan pengaruh antara suatu tayangan di Youtube dengan penontonnya. Data yang diperoleh kemudian diolah dengan menggunakan SPSS versi 16.0. Hasil dari penelitian ini mendapat hubungan yang signifikan antara pengaruh menonton tayangan Youtube "londokampung" dengan tingkat pengetahuan bahasa Suroboyoan pada subscribers di Surabaya. berdasrkan hasil analisis korelasi dan regresi liner sederhana bhawa variabel pengaruh tayangan Youtube "londokampung" memiliki hubungan signifikasi dengan nilai koefisien korelasi 0.581 terhadap variabel pengetahuan bahasa Suroboyoan pada subscribers bernilai sedang. Nilai korelasi pada penelitian ini berada pada interval koefisien antara 0,400-0,599.

Kata-kata Kunci: Youtube londokampung, Pengetahuan Bahasa Surboyoan, Peningkatan Pengetahuan

\section{PENDAHULUAN}

Komunikasi merupakan aktifitas manusia yang sangat penting. Kita semua berinteraksi dengan sesama dengan cara melakukan komunikasi. Komunikasi bisa dilakukan dengan cara yang sederhana, sampai dengan cara yang paling kompleks. Namun saat ini seiring dengan berkembang pesatnya teknologi telah merubah manusia dalam berkomunkasi. (Mulyana 2005:41).

Munculnya beraneka ragam teknologi baru memberikan wawasan dan juga kemudahan dari beberapa aspek kehidupan termasuk dalam berkomunikasi, sehingga masyarakat tidak perlu bertatap muka atau menempuh jarak yang jauh untuk bertemu secara langsung. Perubahan bentuk masyarakat menjadi suatu masyarakat informasi memicu perkembangan teknologi informasi yang dilengkapi dengan perangkat canggih dan informasi beragam sesuai dengan kebutuhan.

Kemunculan kecanggihan teknologi untuk berkomunikasi akhirakhir ini mengakibatkan munculnya dampak positif dan juga negatif, terhadap tata kehidupan masyarakat di berbagai negara, termasuk Indonesia. Berdasarkan realitas yang ada seluruh negara kini kehidupannya ditopang oleh kemajuan teknologi informasi. Kemajuan tersebut ditandai dengan penggunaan alat-alat telekomunikasi seperti jaringan nirkabel, televisi, dan juga pesawat telepon.

Keberadaan suatu informasi menjadi sangat penting di era milenial ini, sehingga tidak heran jika banyak sekali teknologi pendukung yang mampu menyajikan informasi kepada khalayak yang tepat dan cepat, mengingat informasi mempunyai peranan penting diseluruh aspek kehidupan, sehingga ketergantungan akan tersedianya informasi semakin meningkat. (Castells Manuel, 2001:10) Mengatakan "Kemajuankemajuan dalam teknologi informasi diiringi munculnya internet sebagai media dalam mengakses segala bentuk informasi". Internet sendiri muncul dan diciptakan pada tahun 1960 yang bernama ARPANET oleh Profesor di Univeristas Of California, Los Angles. Sementara dalam portal sejarah perkembangan internet di Indonesia, internet baru dimulai pada 
tahun 1994 dan diprakarsai oleh Indonet.

Munculnya internet didukung pula dengan aplikasi-aplikasi yang perlahan dapat membantu serta memenuhi kebutuhan manusia. Secara global kecanggihan internet kini sudah mempengaruhi berbagai bidang, bukan hanya di bidang teknologi itu sendiri, melainkan meluas hingga ke bidang pendidikan, ekonomi, sosial budaya serta bidang politik.

Namun dengan berkembang pesatnya internet kini memunculkan media baru. John Steve dalam Encyclopedia New Media menjelaskan dalam artian luas bahwa media baru atau new media ini adalah istilah yang memayungi penjelasan mengenai kondisi teknologi digital dan internet teraktual, serta dampaknya terhadap budaya di sekitarnya (revolusi digital). New media sendiri memiliki karakteristik seperti dapat dimanipulasi, bersifat jaringan, padat, interaktif, dan tidak memihak. Media baru tercipta dari kebutuhan para penggunanya untuk saling terhubung satu sama lain yang tidak terbatas, contohnya saja jejaring sosial yang kian marak digunakan sebagai media berkomunkasi antar sesama. Saat ini jejaring sosial seperti Instagram dan Youtube lah yang sedang digemari oleh masyarakat.

Menurut data statistik yang diperoleh dari Hootsuite tahun 2019 platform media yang paling aktif adalah Youtube sebanyak 88\%, disusul dengan Whatsapp 83\%, Facebook $81 \%$ dan Instagram $80 \%$. Dilansir dari https://m.youtube.com Youtube sendiri merupakan media sosial penyedia segala informasi dalam bentuk tayangan video, yang mana artinya Youtube merupakan media baru yang berupa audio-visual. Memiliki slogan "Broadcast Yourself" Youtube kini menjadi sasaran utama khalayak untuk mendapatkan informasi. Peran Youtube di Indonesia sebagai sarana publikasi konten video terus meningkat. Jumlah konten yang di unggah di Indonesia meningkat lebih dari dua kali lipat dari tahun ke tahun. Menurut hasil riset Google, 92\% pengguna Indonesia menyatakan Youtube adalah tujuan pertama mereka ketika mencari konten video, secara umum pengguna di Indonesia berpendapat bahwa Youtube memudahkan mereka dalam mencari konten yang menarik dengan topik yang beragam.

Youtube kini menjadi lahan bisnis bagi sebagian penggunanya, bahkan penghasilan yang didapatkan dari Youtube cukup besar, yaitu sekitar 550 USD atau Rp. 7000.000,jika ada sebanyak 1 juta viewers. Di dalam Youtube terdapat istilah subscriber, subscriber merupakan sebutan pagi pengguna Youtube yang berlangganan tayangan tertentu, hal tersebut berfungsi agar pelanggan atau subscriber ini selalu mendapatkan notifikasi video baru dari tayangan yang diikutinya. Salah satu youtuber yang berhasil dengan meraup keuntungan besar adalah Atta Halilintar. Atta Halilintar berhasil mendapatkan penghargaan tertinggi dari Youtube, yaitu berupa Dimond Creator Awards dimana ia mempunyai 14 juta subscriber. (Dilansir dari laman instagram @attahalilintar diakses pada 23/03/2019 pukul 00:04 WIB) yang menjadikannya meraih gelar Youtuber nomor 1 se-Asia. Hal ini kemudian menginspirasi banyak generasi milenial untuk menuangkan bakat dan minatnya dan melahirkan

ISSN 2338 - 0861 (cetak); e-ISSN 2621 - 8712 (online)

website : http://spektrum.stikosa-aws.ac.id 
konten kreator beragam dari seluruh daerah di Indonesia.

Salah satunya berada di wilayah Surabaya, Jatim Timur. Dia adalah Dave Jepchott konten kreator atau Youtuber asli negara Kanguru yang tumbuh dan besar di Surabaya yang kini berhasil menarik jutaan pasang mata di Youtube dengan channelnya yang berjudul "londokampung". Kecintaannya terhadap budaya lokal ini membuatnya tergerak untuk membuat konten Youtube tersebut menyajikan konten Youtube dengan tema budaya lokal, budaya lokal tersebut berupa segala sesuatu yang bersangkutan dengan Surabaya, mulai dari bahasa Suroboyan yang sudah menjadi bahasa ibu arek-arek Suroboyo, kemudian tempat-tempat wisata di Surabaya, hingga makanan khas Surabaya pun menjadi topik yang diangkat di channel Youtube "londokampung".

Bagi Cak Dave kemajuaan zaman yang makin tidak terkendali membuat sebagian orang lupa diri, darimana dirinya berasal, kemudian terkikisnya rasa bangga terhadap budaya dan bahasa sendiri. Menurut Cak Dave bahasa Jawa merupakan bahasa yang sangat unik, untuk itu pada konten Youtubenya Cak Dave selalu menggunakan bahasa Jawa (Suroboyoan) dalam penyampaiannya. Cak dave mulai mengunggah video pertamanya pada tanggal 12 September 2016 dengan judul "Bule Nyanyi Diobok-Obok Versi Jawa" yang mendapatkan 307,648 subscriber. Melihat ketertarikan para warganet akan konten Youtubenya kemudian membuat Cak Dave terus berkarya, hingga sampai tahun 2019 saat ini video "londokampung" mampu meraih 2 juta Subscribers dengan total video sebanyak 209. (diakses pada tanggal 04/05/2019 pukul 20:16 WIB dari Youtube "londokampung".)

Pada penelitian ini, peneliti memilih warga Surabaya yang menjadi subscriber (pelanggan) pada tayangan channel Youtube "londokampung". Alasan pemilihan objek penelitian ini terkait dengan tingkat pengetahuan bahasa Suroboyan. Dimana pada penelitian ini peneliti menggunakan teori sikap untuk mengetahui tiga komponen yakni kognitif, afektif, dan konatif, serta menggunakan teori terpaan media (media exposure) yang memiliki tiga komponen juga yaknni frekuensi, atensi, dan durasi.

Dengan adanya hal ini peneliti ingin mengetahui seberapa besar pengaruh terpaan tayangan channel Youtube "londokampung" bagi para subscribers, maka peneliti mengajukan sebuah penelitian dengan judul "Pengaruh Terpaan Tayangan Youtube "Londokampung" Terhadap Tingkat Pengetahuan Bahasa Suroboyoan Pada Subscribers Di Surabaya

\section{METODE PENELITIAN}

Dalam penelitian pengaruh terpaan tayangan Vlog di Youtube terhadap tingkat pengetahuan Bahasa Jawa Timur (Bahasa Suroboyoan) pada subscribers (studi pada subscribers Channel Youtube "londokampung"). metode penelitian yang digunakan yaitu penelitian kuantitatif.

suatu Penelitian kuantitatif adalah pengetahuan yang menggunakan data berupa angka sebagai alat menemukan keterangan mengenai apa yang ingin kita ketahui. Dalam 
penelitian ini, peneliti ingin mengetahui sejauh mana pengaruh tayangan Vlog di Channel Youtube "londokampung" terhadap pengetahuan Bahasa Jawa (Bahasa Suroboyoan) Subscriber di Surabaya dengan menggunakan pendekatan teori sikap untuk mengetahui tiga komponen yakni kognitif, afektif, dan konatif, serta menggunakan teori terpaan media (media exposure) yang memiliki tiga komponen juga yakni frekuensi, atensi, dan durasi.

Populasi dalam penelitian ini adalah warga Surabaya yang menjadi pelanggan ataupun penonton channel Youtube "londokampung". Dimana pada penelitian ini, peneliti menggunakan kuesioner online yang pengisian kuesioner dan penyebarannya melalui direct message $(\mathrm{dm})$ melalui followers instagram "londokampung" yang berlangganan channel Youtube "londokampung dan juga melalui wawancara. Sampel dalam penelitian ini adalah subscriber akun Youtube "londokampung" yang bertempat tinggal di Surabaya, penarikan sampel darihttps://www.youtube.com/chann el/UCADZVxC_4omYiNDLcsDoCeg dengan jumlah 100 responden. Jumlah 100 orang yang ada akan diberi kuesioner ini ditentukan peneliti dari keaktifannya merespon dan berpartisipasi dalam akun Youtube londokampung. Dari pengamatan selama kurang lebih dua minggu, maka peneliti sudah menentukan beberapa orang yang akan dimintai pendapat melalui kuesioner.

\section{HASIL DAN PEMBAHASAN}

Peneliti melakukan pendekatan melalui kuesioner online kepada Subscriber untuk meminta kesediaanya mengisi kuesioner dengan memenuhi kriteria sebagai berikut : individu yang berdomisili di Surabaya., individu yang aktif menggunakna internet, minimal 1 kali sehari, individu yang mempunyai akun Youtube dan menjadi subscriber channel youtube "londokampung" . Adapun untuk mengetahui jumlah sampel maka digunakan rumus Yamane, untuk selang kepercayaan $90 \%$ dengan presisi $10 \%$.

Teknik analisis data dalam penelitian ini adalah data yang diperoleh dari kuesioner yang telah terkumpul dianalisis menggunakan Regresi Sederhana. Regresi atau peramalan adalah suatu proses memperkirakan secara sistematis tentang apa yang paling mungkin terjadi di masa yang akan datang berdasarkan informasi masa lalu dan sekarang yang dimiliki agar kesalahannya dapat diperkecil (Riduwan, 2012: 96).

Table 1. Tabel Durasi Melihat Tayangan Londo Kampung dalam kurun waktu

satu bulan

\begin{tabular}{|c|c|c|}
\hline $\begin{array}{l}\text { Durasi } \\
\text { Menonton } \\
\text { Tayangan } \\
\text { “londo } \\
\text { kampung" }\end{array}$ & Frekuensi & $\begin{array}{l}\text { Presentase } \\
(\%)\end{array}$ \\
\hline $\begin{array}{l}\text { Menonton } \\
\text { lebih dari } \\
\text { separuh } \\
\text { tayangan } \\
\text { (30-45 } \\
\text { menit) }\end{array}$ & 65 & $65 \%$ \\
\hline $\begin{array}{l}\text { Menonton } \\
\text { sebagian } \\
\text { tayangan } \\
(15-30 \\
\text { menit) }\end{array}$ & 23 & $23 \%$ \\
\hline
\end{tabular}




\begin{tabular}{|c|c|c|}
\hline $\begin{array}{l}\text { Menonton } \\
\text { sebagian } \\
\text { kecil } \\
\text { tayangan (0- } \\
15 \text { menit) }\end{array}$ & 2 & $2 \%$ \\
\hline \multicolumn{3}{|c|}{ Sumber: olahan data peneliti } \\
\hline \multicolumn{3}{|c|}{$\begin{array}{l}\text { Table 2. Tabel Frekueni Melihat } \\
\text { Tayangan Londo Kampung dalam } \\
\text { kurun waktu satu bulan }\end{array}$} \\
\hline $\begin{array}{l}\text { Frekuensi } \\
\text { Menonton } \\
\text { Tayangan } \\
\text { "londo } \\
\text { kampung" }\end{array}$ & Frekuensi & $\begin{array}{l}\text { Presentase } \\
\text { (\%) }\end{array}$ \\
\hline $\begin{array}{l}\text { Sangat Sering } \\
\text { (lebih dari } 8 \\
\text { kali) }\end{array}$ & 55 & $55 \%$ \\
\hline $\begin{array}{l}\text { Sering } \quad \text { (6-7 } \\
\text { kali) }\end{array}$ & 32 & $32 \%$ \\
\hline $\begin{array}{l}\text { Jarang } \quad \text { (3-5 } \\
\text { kali) }\end{array}$ & 10 & $10 \%$ \\
\hline $\begin{array}{l}\text { Sangat } \\
\text { Jarang } \\
\text { kali) }\end{array}$ & 3 & $3 \%$ \\
\hline
\end{tabular}

Sumber: olahan data peneliti

Table 3. Tabel Perhatian Selama Menonton Youtube "londokampung"

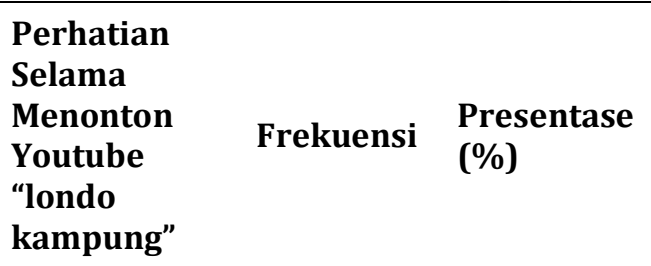

Tidak pernah

diselingi $\quad 54 \quad 54 \%$

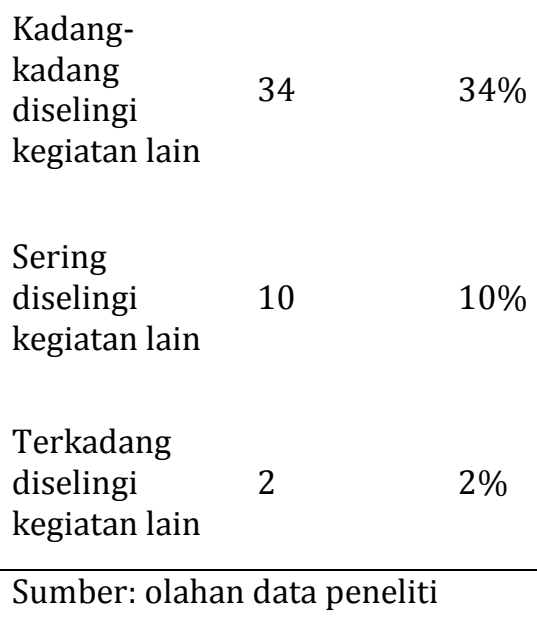

Table 5. Mengetahui Dialek Suroboyoan setelah menonton Youtube "londokampung

\begin{tabular}{lll}
$\begin{array}{l}\text { Kategori } \\
\text { Jawaban }\end{array}$ & Frekuensi & $\begin{array}{l}\text { Presentase } \\
\text { (\%) }\end{array}$ \\
\hline $\begin{array}{l}\text { Sangat } \\
\text { Setuju }\end{array}$ & 59 & $59 \%$ \\
Setuju & 41 & $41 \%$
\end{tabular}

ISSN 2338 - 0861 (cetak); e-ISSN 2621 - 8712 (online) website : http://spektrum.stikosa-aws.ac.id 
Tidak Setuju $\quad 0$

$0 \%$

Sangat

Tidak Setuju

Sumber: olahan data peneliti

\section{Analisa Regresi Sederhana \\ Tabel 6. Hasil Analisis Regresi Sederhana Menggunakan SPPS Windows Version 16.0}

Coefficients

\begin{tabular}{|c|c|c|c|c|c|c|}
\hline \multirow[b]{2}{*}{ Model } & & \multicolumn{2}{|c|}{ Unstandardized Coefficients } & \multirow{2}{*}{$\begin{array}{c}\text { Standardized } \\
\text { Coefficients }\end{array}$} & \multirow[b]{2}{*}{1} & \multirow[b]{2}{*}{ Sila. } \\
\hline & & B & Std Error & & & \\
\hline & (Constant) & 30.594 & 2.299 & & 13.306 & .000 \\
\hline & SUMX & 1.415 & .200 & .581 & 7.068 & .000 \\
\hline
\end{tabular}

Tabel 7 Hasil Analisis Koefisien Relasi Model Summary

\begin{tabular}{|c|c|c|c|c|}
\hline Mode & $\mathrm{R}$ & R Square & $\begin{array}{l}\text { Adjusted R } \\
\text { Square }\end{array}$ & $\begin{array}{l}\text { Stdd Error of } \\
\text { the Estimate }\end{array}$ \\
\hline 1 & $581^{3}$ & .338 & .331 & 3.891 \\
\hline
\end{tabular}

Tayangan Channel "londokampung" Pada Platform Youtube. Data disajikan untuk mengukur pengaruh tayangan channel "londokampung" pada platform Youtube dilihat dari tingkat keseringan subscribers dalam menonton tayangan "londokampung" dalam jangka waktu satu bulan.

Berdasarkan tabel diatas, diketahui pada tabel frekuensi, sebagaian besar atau mayoritas responden yang merupakan subscribers channel youtube "londokampung" di Surabaya yaitu lebih dari 8 kali dalam satu bulan. Hal ini menunjukkan bahwa mayoritas responden berada pada kategori Sangat Sering menonton tayangan "londokampung" di Youtube.

Pada tabel durasi terlihat bahwa sebagian besar responden yaitu 65 responden (65\%) lama menonton 0-60 menit tayangan "londokampung" dalam satu kali menonton atau video, hal ini menunjukkan bahwa mayoritas responden berada kateogori Lama atau Full video dalam menonton tayangan "londokampung" di Youtube yaitu menonton sampai selesai.

Sedangkan pada aspek atensi atau perhatian yang diberikan responden pada saat menonton tayangan "londokampung" di Youtube. Sebanyak 54 responden (54\%) menyatakan bahwa tidak pernah menyelingi dengan kegiatan lain saat menonton, 34 responden (34\%) menyatakan bahwa kadang kadang menyelingi kegiatan lain saat menonton 10 responden (10\%) menyatakan bahwa sering menyelingi dengan kegiatan lain saat menonton dan sisanya 2 responden (2\%) menyatakan terkadang menyelingi dengan kegiatan lain saat menonton tayangan "londokampung".

Setelah menonton Youtube "londokampung" responden yang merupakan subscribers menyatakan mengetahui Bahasa Jawa (Suroboyoan). Hal ini dibuktikan dengan terdapat 68 responden (68\%) menyatakan sangat setuju, 32 responden $(32 \%)$ menyatakan setuju, Oresponden $(0 \%)$ menyatakan tidak setuju dan tidak ada responden (0\%) yang menyatakan sangat tidak setuju.

Selain itu, dapat diketahui responden yang mengetahui dialek Bahasa Surabaya setelah menonton Youtube "londokampung", yakni 
sebanyak 59 responden (59\%) menyatakan sangat setuju, 41 responden $(41 \%)$ menyatakan setuju, 0 responden $(0 \%)$ menyatakan tidak setuju dan tidak ada responden $(0 \%)$ yang menyatakan sangat tidak setuju.

Nilai koefisien korelasi (R) menunjukkan seberapa erat pengaruh antara variabel pengaruh tayangan "londokampung" di Youtube (X) dengan variabel pengetahuan bahasa jawa (Bahasa Suroboyoan) (Y).

Berdasarkan hasil penghitungan di atas, diperoleh persamaan regresi linier sederhana sebagai berikut :

$\mathrm{Y}=30.594+1.415 \mathrm{X}$

$\mathrm{Y}=$ Pengetahuan Bahasa Jawa (Bahasa Suroboyoan)

$\mathrm{X}=$ Pengaruh Tayangan channel "londokampung" Pada Platform Youtube

Adapun intrepretasi dari model regresi linier sederhana di atas adalah sebagai berikut : Konstan (a) yang dihasilkan sebesar 30.594 menunjukkan bahwa pengetahuan bahasa Jawa (Bahasa Suroboyoan) (Y) sebesar 30.594 satu-satuan jika variabel pengaruh tayangan channel Youtube "londokampung" (X), bernilai konstan.

Nilai koefisien pengaruh Tayangan Channel Youtube "londokampung" sebesar 1.415 menunjukkan bahwa jika variable tayangan channel Youtube "londokampung" (X) ditingkatkan satu-satuan maka akan mengakibatkan peningkatan Pengetahuan Bahasa Suroboyoan (Y) sebesar 1.415 dengan asumsi variabel lain konstan.

Besarnya nilai koefisien korelasi adalah sebesar 0,581. Nilai tersebut menunjukkan hubungan variabel pengaruh tayangan "londokampung" di Youtube (X) pengetahuan bahasa jawa (Bahasa Suroboyoan) subscribers di Surabaya (Y) bernilai sedang karena nilai korelasi tersebut berada pada interval koefisien antara 0,400 - 0,599.

Nilai koefisien Determinasi $\mathrm{R}$ Square menunjukkan bahwa kontribusi determinasi pengaruh tayangan "londokampung" di Youtube (X) dengan variabel pengetahuan bahasa jawa (Bahasa Suroboyoan) subscribers di Surabaya (Y) sebesar $33,8 \%$ yang berarti sisanya $66,2 \%$ dipengaruhi oleh variabel lain di luar model yang diteliti.

\section{KESIMPULAN}

Dari hasil penelitian ini dapat disimpulkan bahwa hasil keseluruhan responden ini menunjukkan tayangan "londokampung" mempunyai pengaruh yang cukup signifikan terhadap peningkatan pengetahuan Bahasa Jawa (Bahasa Suroboyoan) pada subscribers di Surabaya yang didukung oleh faktor terpaan media seperti frekuensi, durasi dan atensi.

Data yang ada dianalisa dan dihitung menggunakan regresi sederhana serta koefisien relasi.

\section{DAFTAR PUSTAKA}

Allan. 2005. Pengertian internet dan asal usul dari kata internet. Indah: Surabaya

Ardianto Elvinaro. 2007. Komunikasi Suatu Pengantar: Simbiosa: Rekatan Media, Bandung

Berge, Charles R and Steve A. Chafee. 1983. Handbook Communication Science. Beverly Hills : Sage Production 
Bimo, Walgito. 2003. Pengantar Psikologi Umum, Yogyakarta : ANDI

Bittner. 1980. John R. Mass Communication, an Induction. Prentince Hall.

Budiargo, Dian. 2015. Berkomunikasi ala Net Generation. PT.Elex Media Komputindo Kompas Gramedia: Jakarta

Cangara, Hafied. 2002. Pengantar Ilmu Komunikasi. PT. Raja Grafindo Persada: Jakarta

Castells, Manuel, 2001. The Internet Galaxy, Reflection On The Internet, Business and Society. Oxford University Press

Effendi, Onong Uchjana. 1993. Ilmu, Teori, dan Filsafat Komunikasi, Bandung: PT. Citra Aditya Bhakti

Effendi, Onong Uchjana. 1993. Ilmu, Komunikasi Teori dan Praktek, Bandung: Remaja

Jalaludin Rakhmat. 2007. Metode Penelitian Komunikasi, Bandung: PT. Remaja Rosdakarya

Jalaludin Rakhmat. 2008. Psikologi Komunikasi, Bandung: PT. Remaja Rosdakarya

John, Steve, 2003. Encyclopedia New Media. Sage publication

Keraf, Gorys. 2001. Diksi dan Gaya Bahasa. Gramedia Pustaka Utama: Jakarta

Krisyantono, Rachmat, 2006. Teknik Praktis Riset Komunikasi, Edisi Pertama, Jakarta : Kencana

Littlejohn, Stepthen W \& Karen A. Foss. 2009. Teori Komunikasi, edisi 9. Jakarta: Salemba Humanika

Mulyana, Deddy. 2005. Ilmu Komunikasi Suatu Pengantar. PT. Remaja Rosdakarya

Olson, J.M., and M.P Zanna. 1993. Attitudes ang Attitude Change.
Annual Review of Psychology, 44:117-154.

Prakoso, Kukuh. 2009. Lebih Kreatif Dengan Youtube. Andi Offset: Yogyakarta

Singarimbuan, Masri. 1995. Metode Penelitian Survei. LP3S. Jakarta

Sugiono, Prof, DR, 2003. Statistika Untuk Penelitian, Bandung: Alfabeta

Suprapto, Tommy. 2006. Pengantar Teori Komunikasi, Yogyakarta: Media Pressindo

Suryanto, Dr., M.Si, 2015. Pengantar Ilmu Komunikasi, Edisi Pertama, Pustaka Setia.

Sobur, Alex. 2016. Psikologi Umum Edisi Revisi. Pustaka Setia

Widiowatie, Sri Derta (Penerjemah). 2014. Handbook Ilmu Komunikasi. Bandung: Nusa Media

\section{Non Buku}

https://www.youtube.com/channel/ UCADZVxC_4omYiNDLesDoCeg

https://andi.link/hootsuit-we-aresocial-indonesian-digital-report2019/

https://www.youtube.com/

instagram@attahalilintar

Ramli, Kamrianti. 2013. pengertian sikap menurut oara ahli. http://kamriantiramli.wodpress. com/ diakses pada tanggal 22/06/2019 pukul 08.30 WIB)

https://www.google.com/amp/s/hen rinurcahyo.wordpress.com/2007 /09/29/kamus-dialek-suroboyoabjad-amp/ (diakses pada tanggal 21/06/2019 pukul 00.44 WIB) 